\title{
ON THE MACHINERY FOR WEAVING BRUSSELS CARPET BY POWER.
}

\author{
By Mr. WILLIAM WeILD, of Manchester.
}

In Carpets and other pile fabrics, there are interwoven, between the threads of the ordinary plain fabric forming the body or back of the carpet, other threads, generally of a different material, which are interwoven in such a manner as to form a terry, looped, or pile surface. In the actual weaving there is therefore little difference between pile fabrics and plain or jacquard fabrics, the additional mechanism required for the pile fabrics being only such as will form the pile threads into loops on the surface of the fabric during the process of weaving. The substitution of self-acting machinery for weaving carpets and other pile fabrics, in place of the previous hand labour, has occupied the particular attention of machinists for more than twenty-five years, and many arrangements have been invented for effecting this object; but it was only between 1851 and 1856 that machinery for the purpose was so far perfected as to be commercially successful.

There are two classes of pile fabrics: those in which the pile is formed by the "weft" (the threads passing crossways of the piece); and those in which it is formed by the "warp" (the threads passing lengthways of the piece): but it is only the latter class that is referred to in the present paper. 'Various methods of weaving warp-pile fabrics have been proposed, some of which are in use at the present time. Hat-plush or velvet is manufactured by weaving two pieces at the same time, face to face, the pile warp being bound alternately in each piece; and the two pieces are afterwards separated by cutting the connecting pile, so that each piece contains half of the pile warp. Terry or looped fabrics have been manufactured in various ways; but the method most usually adopted for forming the loops of the pile is by means of wires placed in the 
"shed," that is the opening between the threads through which the wire passes across the fabric. This plan is practised in weaving by hand, and is generally admitted to be the best method yet known for making a good and regular terry or looped pile-fabric. The wire is introduced into the shed between the pile threads and the body warp, so that when the pile threads are afterwards bound down again in the body of the fabric they form loops over the wire, which is subsequently withdrawn from the fabric. The object aimed at in most of the inventions for weaving pile fabrics by power with the use of wires has been to combine mechanism for inserting and withdrawing the wires with the mechanism of the ordinary power loom employed for weaving either plain or jacquard patterns.

Three descriptions of warp-pile fabrics are manufactured, which are known as Tapestry carpet, Brussels carpet, and Velvet or Cutpile carpet, the construction of which is illustrated by the diagrams Figs. 12 to 14, Plate 104.

In Fig. 12 is shown a longitudinal section of a Tapestry carpet, with a shed formed for the new wire $A$ to be inserted. The body of the fabric is formed by the two sets of warp threads B B, which are generally linen threads; these are interwoven with the weft, the threads of the weft being seen in section in the diagram; and in addition there is generally a warp of thick soft threads $\mathrm{C}$, for the purpose of giving sufficient thickness and substance to the fabric. In this construction of carpet these thick threads $\mathrm{C}$ remain always in the middle of the fabric, and the weft passes above and below them across the carpet, as shown in the diagram. The pile threads $\mathbf{D}$ never descend below the thick threads $\mathrm{C}$, and consequently never appear at the back of the carpet; and in the operation of weaving the whole number of the pile threads are raised and lowered simultaneously; when raised they form the shed for the new wire A to be inserted beneath them, as shown in Fig. 12. Where there are designs in colour upon a tapestry carpet, they are produced by each separate pile thread being made parti-coloured and arranged in such a manner that when woven over the wires a pattern is produced by plain weaving. 
In Fig. 13, Plate 104, is shown a longitudinal section of a Brussels carpet, with a shed open for the new wire A to be inserted. Here the body warp B is the same as for tapestry carpet, but there are five times as many pile threads DD as in tapestry carpet, and not more than one-fifth of the whole number of pile threads are raised simultaneously to form the shed for inserting the wire; the other four-fifths of the pile threads take the position of the thickening warp $\mathrm{C}$ in tapestry carpet. Some of the pile threads are only required to ascend and form loops at long intervals in the pattern, and the consumption of the same thread varies at different times according to the requirements of the pattern. Consequently a greater length of some pile threads is necessary than of others, and each pile thread therefore has here to be placed upon a separate bobbin; whereas for tapestry carpet all the pile threads are wound off a single long roller. The design in Brussels carpet is formed by the jacquard, each pile thread being of some particular colour throughout from end to end; and the jacquard draws up those threads which are of the colour required to produce the pattern.

In Fig. 14, Plate 104, is shown a longitudinal section of a Velvet or Cut-pile carpet. This is similar in construction to Brussels carpet, except that two shoots of weft are used to tie down each loop of the pile more securely; and the pile threads being woven over wires of deep section, as shown exaggerated in the diagram, the loops are afterwards cut open in withdrawing the wires, so as to form the velvet surface, as shown at $\mathrm{E}$. The wires used for weaving velvet pile are shown full size in the side and edge views, Fig. 15, a knife $F$ being formed at the outer end of each wire for the purpose of cutting open the loops in withdrawing the wire.

In Figs. 16 to 18, Plate 104, are shown diagrams of the three sheds required in weaving Brussels carpet. The shed in Fig. 16 is one for the shuttle, where all the pile threads $D$ have been lifted as well as half of the body warp $B$, the other half of the body warp $B$ being down; and the shuttle $G$ then puts in the bottom shoot of weft that comes upon the back of the fabric. The shed shown in Fig. 17 is the next one formed, and is also for the shuttle, all the pile threads $D$ being down, while the two halves of the body warp B B 
remain in the same positions as previously; and the shuttle $G$ then puts in the top shoot of weft, which ties down the loops formed upon the last wire inserted. The third shed, shown in Fig. 18, is for inserting the next wire $A$; here all the body warp threads $B$ and pile threads $\mathrm{D}$ are down, except those pile threads that are lifted by the jacquard, which are to form the loops upon the new wire.

In the first attempt to apply self-acting machinery for working the wires, they were drawn out one by one as required from a bundle of wires, and were carried through the shed by a pair of nippers fixed at the end of a reciprocating rod; and after having been woven into the fabric and then withdrawn from the loops, the wires were returned by hand to the bundle. Next the whole operation was rendered self-acting, by dropping wires successively from a hopper into a longitudinal groove in a rod, which was pushed through the shed in guides, and was then caused to make a half revolution by means of a screw incline on the rod, so as to drop the wire into its place in the shed; and the wires were withdrawn successively from the fabric by reciprocating nippers, and carried up again into the hopper by endless chains. Afterwards an improvement was made by placing the wires singly in a trough, from which each in succession was pushed into the shed; and the wires were made with a hook at the back end of each, by means of which each was drawn out of the fabric successively by an endless chain, and was then transferred to the feeding trough for insertion again into the shed.

In the early application of machinery for working the wires, it was assumed that for wide fabrics, such as carpets, the wire could not be passed through the shed without being supported in its passage, on account of the deflection of its free extremity; various contrivances were therefore employed for supporting the wire as it passed through the shed, the wire being pushed from a trough used as a guide. It has since been found practicable however for the wires used in carpet weaving to be introduced without having supports in the shed; and this is done in the loom now extensively employed by Messrs. Crossley of Halifax, which comprises the important improvements of the late Mr. Collier. In this loom at 
horizontal slide works in a long guide which is attached to arms fixed on a horizontal shaft below, so that the guide and the slide can be oscillated longitudinally in the loom between the positions for drawing the wire out of the fabric and inserting it again in the shed; the slide is made with a holder for holding the end of the wire. For drawing the wire out of the fabric a sliding hook is used, which is actuated by a crank; this hook takes hold of the bow on the end of the wire, and by the time it has drawn the wire nearly out of the fabric, the holder on the inserting slide has arrived opposite to it, and the end of the wire is jammed into the holder by the hook; the movement of the hook in the outward direction then ceases, but the sliding holder still continues its back movement until the wire is clear of the fabric and hook. When drawn out of the fabric the free end of the wire is received in a directing fork, which has an oscillating movement imparted to it longitudinally, corresponding with that of the oscillating frame carrying the inserting slide. The directing fork and the inserting slide then together carry the wire to the position for insertion into the shed; and during the time it is being inserted, they still continue their oscillating movement towards the wider part of the shed, until the wire is inserted to the full length. The inserting slide stands still while the wire is beaten up by the reed and bound in by the pile threads; after which it begins to slide outwards, releasing its hold of the wire, and at the same time the oscillating frame moves towards the point where the next wire is being withdrawn from the fabric, so that the sliding holder may be ready to receive the wire from the drawing-out hook in the manner already described. These movements are repeated for each wire inserted.

The arrangements previously referred to for working the wires in weaving pile fabrics have been for working a number of loose wires, where there are always ten to thirty wires or more remaining at the same time in the fabric during its manufacture: this method of working the wires is therefore known as the "loose wire" system. There is however another method of working the wires, called the "fast wire" system; and the first plan for working the wires on this system by self-acting arrangements in hand looms 
for weaving narrow fabrics was invented in 1842 by $\mathrm{Mr}$. Thompson of Coventry. Two wires are here used, one on each side of the fabric, and fixed at the outer end to arms or holders; these arms have successive movements whereby they withdraw each wire alternately from the fabric, then move it to the widest part of the shed and insert it in the shed, and then bring it back to the "fell" or point of beat up. At present however it is believed very few, if any, of this class of looms are employed. Manufacturers in general have an objection to looms in which only two wires are used, being of opinion that a good carpet pile fabric cannot be produced by that plan; and it may be presumed that this objection has some foundation, otherwise the improvers of this class of looms would not have departed from the simplicity of the two-wire loom by adding arrangements for working four wires, which render such looms very complex.

In the methods of working the wires on the loose-wire system there is considerable uncertainty in the mechanism, although it is probable that the various plans which have been described may all have been intended originally to act at very slow speeds; bat it is rapid motion that developes the uncertainty and incorrect operation of the mechanism. In the improved loom about to be described however, which has been invented by the writer and made by Messrs. Sharp Stewart and Co., the previons defects are now so greatly diminished that the uncertainty of action may be considered to be entirely obviated. The new method of working the wires combines the advantages of both the systems previously described, namely the advantage of good quality in the fabric in consequence of using a number of wires, and also the advantage of the certainty of action belonging to the fast-wire loom, since the wires are never released or detached from the mechanism by which they are actuated. The movements of the wires are practically reduced to a simple reciprocation, as they may be considered to be virtually fixed in position.

This construction of mechanism for working the wires is known as the "roller wire-motion," and is shown in Figs. 1 to 11, Plates 
98 to 108 , in the improved form that is extensively used at the present time. Fig. 1 is a sectional side elevation of a Brussels carpet loom, showing the creel frames for the five sets of pile bobbins, the jacquard, and some of the principal parts of the loom. Fig. 2 is a longitudinal section of the loom to a larger scale; and Fig. 3 is a front elevation.

At the middle of the framing of the loom is the crank shaft $\mathrm{C}$, Fig. 2, which actuates the "slay swords" or pair of arms B B carrying the reed $S$ and the shuttle race $G$, and vibrating upon a shaft at the lower part of the frame. of the loom: the position which the slay occupies at the "fell" of the fabric, when it has beaten up the weft or the wire, is shown by the dotted lines in Fig. 2. The cam shaft $D$ is placed under the crank shaft $C$, and carries at one end the tappets from which the healds $\mathrm{E}$ are worked, Fig. 2, for lifting and depressing the threads forming the body warp of the carpet. Upon the cam shaft D are also fixed two arms F F carrying rollers, Fig. 3, which actuate through bell-crank levers the two picking arms $\mathrm{H} \mathrm{H}$; the free ends of these arms working through a slot in the shuttlebox give motion to the picker or shattle. The comberboard I, Fig. 1, is carried by a pair of vertical sliding rods, one on each side of the loom, and receives the required up and down movement by means of a lever from a cam on the cam shaft $D$; the weight to be lifted by the comberboard is partly counterbalanced by weights on the tail end of the lever. The comberboard has as many holes in it as there are pile threads, and the cords J, Fig. 2, which actuate the pile threads pass through these holes, one through each; a knot which will not pass through the hole is made upon each cord a little above the comberboard, so that when the board is lifted all the pile threads are lifted together to form the shed for the bottom weft which crosses underneath the pile warp. The weights $K$ suspended to the cords bring down each cord and its pile thread after it has been lifted. The jacquard L, Fig. 1, which is of ordinary construction, is actuated by a cam apon the cam shaft $D$; and the trap board lifts the successive selections of pile threads intended to form the loops upon the wires.

The five sets of pile threads are supplied from creels carried in the five creel frames MM, Fig. 1, each thread being wound on a 
separate creel. A plan of one of the creel frames is shown to a larger scale in Fig. 4, Plate 101; and a side elevation, partly section, in Fig. 5. A weight for giving tension to the thread is hung upon each thread, between the creel and a wire over which the thread passes, as shown in Fig. 5. The body warp threads are placed upon the two long rollers $\mathrm{N} \mathrm{N}$ at the end of the loom, Figs. 1 and 2, half the entire number of threads being upon each roller; and the threads are drawn off each roller over a smaller vibrating roller, which allows them to give way to the working of the healds $\mathbf{E}$. The carpet newly woven is received upon a plate $Q$, Fig. 2 , extending across the loom, and then passes over a guide roller to the taking up roller $\mathrm{P}$, which is made of wood and studded with short spikes, so as to drag the carpet along as fast as it is woven, and deliver it to be wound upon the receiving roller $Q$ placed below. This last roller is rotated by a ratchet-wheel and paul, which is actuated by a spring attached to one of the slay swords $\mathbf{B}$; the use of a spring for this purpose prevents the possibility of winding up the carpet any faster than it is delivered by the spiked roller $\mathrm{P}$.

The Roller Wire-Motion, or mechanism for working the wires, is fixed on one side of the loom, as shown at $R \mathbf{R}$ in the front elevation Fig. 3, Plate 100; and the construction of the mechanism is shown to a larger scale in Figs. 8 to 11, Plates 102 and 103. Figs. 8 and 9 are a front elevation and plan of the wire motion, showing one of the wires $A$ in the act of being inserted into the shed of the fabric; and the plan shows a portion of the carpet already woven, and the reed $S$ for beating up the weft or the wire. Fig. 10 is a transverse section, half full size, of the roller $\mathrm{R}$ in its casing $\mathrm{E}$, with the slide $\mathrm{T}$ for inserting and withdrawing the wires; and Fig. 11 is an end elevation showing the arrangement for rotating the roller of the wire motion. Figs. 6 and 7, Plate 101, show a full-size side view and edge view of one of the wires.

The roller $\mathbf{R}$ and its casing E, Figs. 8 and 9, Plate 102, are rather longer than the width of the carpet to be woven; and the upper part of the casing $\mathrm{E}$ is cut away through the extent of one sixth of the circumference of the roller, as shown in Fig. 10. Six longitudinal 
grooves are formed in the surface of the roller, of a width and depth corresponding to the diameter of the wires used. The roller in its casing is placed horizontally at one side of the loom, with its end about 9 inches from the edge of the carpet, and with the upper surface of the roller level and parallel with the "fell" of the fabric, as shown in Figs. 8 and 9. At that end of the casing nearest to the carpet, a recess is formed between the end of the roller $R$ and a hoop I concentric with the roller; and in this recess, which extends through one sixth of the circumference of the roller, the heads of the wires are held when inserted in the fabric, as shown in the plan, Fig. 9, each wire having a head of the form shown in Fig. 6. The hoop I keeps the heads of the wires down in their places when inserted into the fabric, and prevents the wires from being pushed too far into the carpet; while the end of the roller prevents them from being withdrawn before the proper time. A projection upon the end of a spring $J$ attached to the side of the casing keeps the heads of the wires erect, pressing them against each other and against the end of the recess, during the whole time that the wires remain inserted in the carpet. At the opposite or outer end of the roller $\mathbf{R}$ there is a projecting collar formed all round the roller, between the end of the casing $\mathrm{E}$ and a hoop carried by a bracket; and this collar has six grooves in it to receive the heads of the wires, so as to keep the heads in their correct radial position while being carried round by the roller in the direction shown by the arrow in Fig. 10. When the roller is stationary, two of its six grooves are opposite the two extreme wires in the recess I, Fig. 9 : one being opposite the wire last inserted into the fabric, and the other opposite the wire next to be withdrawn from the carpet. The other four grooves have each a wire lying in them, as shown in Fig. 10, so that each time the roller is turned through one sixth of a revolution, one wire is brought round to the place for insertion into the shed of the fabric, and the wire last withdrawn from the carpet is carried away.

On the front of the casing $\mathrm{E}$ a slide-way is formed parallel to the axis of the rollez $\mathbf{R}$, Figs. 8 to 10 , upon which is fitted a slide $T$, carrying the finger $U$ for inserting the new wire, and the paul $V$ for withdrawing the last wire. The finger $U$ is hinged upon the 
slide $\mathrm{T}$ by a spring joint, as shown in Fig. 10, so as to be held steady when either up or down. When down, as in Fig. 10, it slides against the inserting edge of the casing $\mathrm{E}$; and a recess in the extremity of the finger fits over the head of the wire that is being inserted, so that as the slide $T$ traverses inwards towards the carpet, the finger $U$ pushes the wire forwards into the shed, holding it down all the time in the groove of the roller. When the slide arrives at the inner end of its traverse, nearest to the carpet, the paul V is tripped up by the head of the wire to be withdrawn, and drops on the inner side of the head, and the wire is then withdrawn from the carpet by the paul during the outward traverse of the slide $\mathrm{T}$. In order to prevent the wire while being withdrawn from getting out of the groove in the roller $R$, several curved fingers $\mathrm{K} \mathrm{K}$ are used, jointed to the underside of the casing $\mathrm{E}$; the ends of these fingers cover the groove which receives the wire withdrawn, as shown by the dotted lines in Fig. 10, and each finger is pressed down upon the roller by a spring acting against the side of the hole throngh which the finger passes in the casing $\mathrm{E}$. These fingers have to be lifted out of the way successively in order to allow the head of the wire to pass; and this is done by a double incline $\mathrm{L}$ upon the bottom of the slide $\mathrm{T}$, which acts upon the projecting tail of each finger in succession during the traverse of the slide.

The slide $T$ receives its traversing motion from a rope $X$, Figs. 8 and 9 , which is secured in a hole in the slide by a block and set screws, Fig. 10; this rope passes over guide pulleys at the ends of the roller casing $\mathrm{E}$, and then to the pulley $\mathrm{Y}, \mathrm{Fig}$. 3, to which the two ends of the rope are secured. The shaft of the pulley $\mathrm{Y}$ carries a pinion gearing with the toothed sector $W$, which is centred at the top in the framing of the loom, and is worked backwards and forwards by a drum cam upon the cam shaft D, Fig. 3. This cam is shaped to produce a quick forward traverse of the slide $T$, so as to insert the wire quickly while the shed is held open for it; but the cam gives a slower backward traverse to the slide, so as to withdraw the wire slowly, having more time to do this in, as a wire is inserted only at every third shed. 
After each wire has been inserted in the fabric, the wire roller $\mathbf{R}$, Fig. 10, is turned round through one sixth of a revolution in the direction of the arrow, by means of the mechanism shown in Fig. 11, Plate 103. The cam M, Figs. 3 and 11, on the end of the cam shaft D of the loom, gives motion to a lever oscillating upon a centre in the framing of the loom; and the other end of this lever has a forked paul jointed to it, which is kept pressed by a spring against the pins in the disc $N$ secured upon the end of the wire roller R, Figs. 8 and 9 ; the extent of movement of the lever and paul is shown by the dotted lines in Fig. 11. The wire roller is held steady after each turn by a $\mathbf{T}$ piece sliding vertically, which is pressed upwards by a spring against the pins in the dise $\mathrm{N}$, as shown in Fig. 11 .

The wires lying in the grooves of the roller previous to insertion into the fabric project 2 or 3 inches beyond the inner end of the roller; and if the point of the wire went straight forwards, as pushed from the groove in the roller, it would be impossible to make it enter the shed correctly, as it would then be so close to the "fell" of the fabric or angle of the shed that the point of the wire would inevitably catch the threads forming the shed. The wire is consequently sprung or deflected upwards and to one side, as shown at $A$ in F'igs. 3,8 , and 9 , by means of the short grooved guide $\mathrm{Z}$, through which the wire passes as it is pushed out of the roller groove. The guide $Z$ is fixed upon the top of a vertical rod, which is moved up and down by a lever actuated by a carn; and when the wire has been pushed nearly through the shed, the guide is lowered into the position shown by the dotted lines in Fig. 8 , so as to be out of the way of the wire at the moment of its being beaten up by the reed; after which the gride is lifted again, so as to be ready for the insertion of the next wire. The springing of the wires by the guide in directing them into the shed might at first sight appear objectionable; but the amount of this bending does not exceed what they will recover by their own elasticity, and the experience of working during many years has proved it to be a great advantage, because the bending stiffens the wire and makes its point steadier whilst passing through the shed. Besides this, in consequence of the angle at which the guide causes the wire to enter the shed, the 
point of the wire comes into a wider part of the shed the further it passes through the shed; and thus, as the unsteadiness of the point of the wire increases with the greater length unsupported in the shed, more space is allowed for its vibration, without risk of its catching the threads forming the shed.

Owing to the position of the roller wire-motion at one side of the loom, the shuttle-box on that side has to be made detached from the slay B B, Figs. 2 and 3, and carried by separate "slay swords" which oscillate upon a shaft coinciding with the sbaft for the slay $B$ B. This loose shuttle-box is actuated by a cam upon the crank shaft $\mathrm{C}$ of the loom, which acts upon a roller in a rod jointed at one end to the shuttle-box; the other end of the rod is slotted to slide upon the crank shaft as a guide. The cam is shaped so as to actuate the loose shuttle-box in such a manner that it will come opposite to the slay B B and have a motion identical with it at the time the shattle is passing across the shed.

This loom will weave 3 inches of carpet per minute, and as much as 47 yards has been woven in one day of ten hours, including. stoppages. The average production per day of ten hours is 42 yards of carpet, which is an important increase over the production of the previous constructions of looms.

Mr. WEILD exhibited a specimen of the roller wire-motion, showing its action, with samples of the different kinds of wires used.

Mr. C. W. Siemens enquired how long this motion had been in use in carpet looms.

Mr. WEILD replied it had been at work for twelve years, and was now extensively used, having been found superior to the other plans both in the speed at which it could be worked, on account of the certainty of its action, and also because it was free from the liability of the wire missing its course when passed into the shed and getting its 
end pushed up through the warp. The wires were held firmly in the grooves of the roller by the series of curved fingers, which were successively lifted and dropped again in the passage of the slide by the inclined plane upon the slide; and whilst the wire was being passed into the shed it was held firmly all the time at the back end by the spring finger of the slide, and the free end of the wire was steadied by being sprung on one side by the grooved guide, which stiffened the wire at the time by the elastic strain put upon it; by this means the free end was so well steadied as to prevent the risk that occurred in other looms of its catching the warp threads, although this loom was worked at a higher speed. The side springing of the wires did not strain or bend them permanently, as they were of hard steel and very carefully made.

Mr. W. Richardson asked what was the difference of speed, and how many yards per day could be woven by hand looms.

Mr. WEITD replied that this loom put in 27 wires per minute as compared with 21 per minute in the other looms; but in hand weaving the speed was only about 3 to 4 wires per minute.

Mr. W. RICHARDson enquired whether the roller motion laid the wires in quite as regularly as hand work; and whether the same motion was suited to the work of all looms.

Mr. WEILD replied that the regularity of the machine work was perfect in laying the wires and beating them up; and one pattern of machine suited all looms, because there was one standard make for all Brussels carpets, namely 8 wires per inch of length, and 27 inches width of carpet. The difference in the work involved in the carpets was in the number of coloured threads used in the pile warp for forming the pattern, and in the best carpets these amounted to the inmense number of 1300 threads, all of which had to be brought up to the surface in turn and all kept in order. About one fifth of the whole number had to be picked up by the jacquard at each insertion of a wire, to ensure the wire being completely covered all across the fabric. There were also the threads of the body warp to be added, for forming the foundation of the fabric; and these raised the total number of threads to about 1700 in the best carpets, each one of which had to be passed through an 
eye in a separate cord, so as to be picked up individually whenever required.

The Chairmas asked what attendance a loom required in working.

Mr. WEILD replied that one man attended to one loom, and a boy attended to the creels of two looms, his business being to change the spools of warp threads as they became emptied.

The ChaIrmax remarked that it was a very ingenious and interesting piece of machinery which had been described; and he moved a vote of thanks to Mr. Weild for his paper and the specimens exhibited, which was passed.

The Chatrman proposed a vote of thanks, which was passed, to the Honorary Local Secretaries, Mr. John Fernie and Mr. W. E. Marshall, for the excellent arrangements they had made for the meeting of the Institution in Leeds; and also to the authorities of the Philosophical Hall for their kindness in granting the use of the Lecture Theatre for the purpose of the meeting; and to the several Railway Companies for the special facilities they had so kindly afforded to the Members for attending the Meeting in Leeds and the Excursions in connection with the meeting.

The Meeting then terminated.

In the afternoon an Excursion was made by the Members by special train to the Works of Messrs. Titus Salt, Sons, and Co., at Saltaire, where the new Corliss Engines were seen at work; and the Members were very handsomely entertained at the Works by Mr. George Salt, and returned to Leeds in the evening. 
On Thursday, 30th July, the Members visited the Tingley Colliery, where the two different Coal-Cutting Machines described at the Meeting-the Pick and the Straight-action Machine-were both seen at work in the pit. The Shale Oil Works and Brick Machinery at Tingley and the new Blast Furnaces at Ardsley, belonging to the West Yorkshire Coal and Iron Company, were also shown to the Members.

The Members also visited the Steam Plough and Locomotive Works of Messrs. John Fowler and Co. in Leeds, where the new Wire-Rope Travelling Crane described at the Meeting was seen at work.

On Friday, 31st July, an Excursion was made by the Members by special train to Scarborough, visiting at York on the way the new Lendal Iron Bridge and the Minster; and they were invited to Dinner in the evening by the Local Committee at the Grand Hotel, Scarborough, in celebration of the Leeds Meeting of the Institution. 


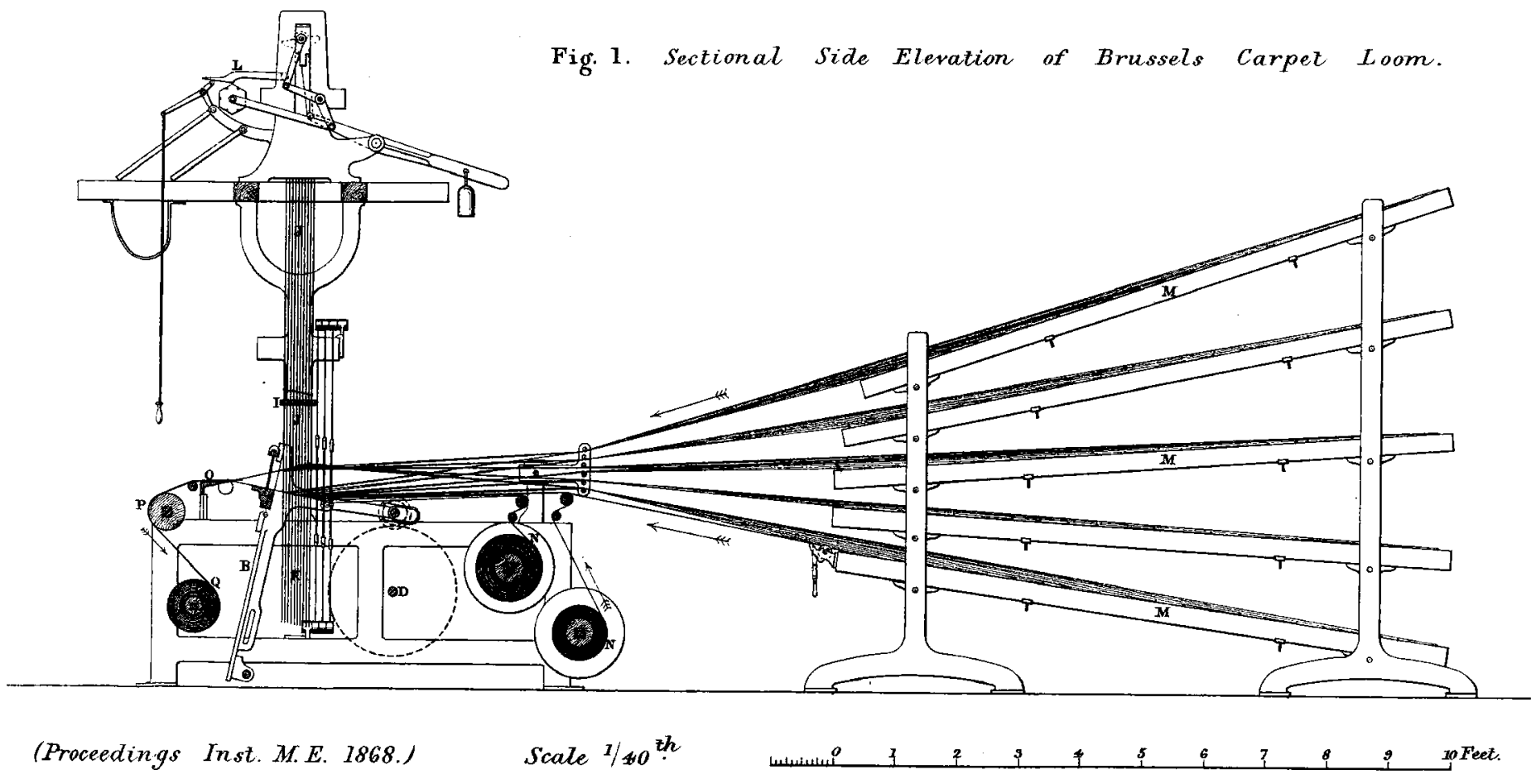




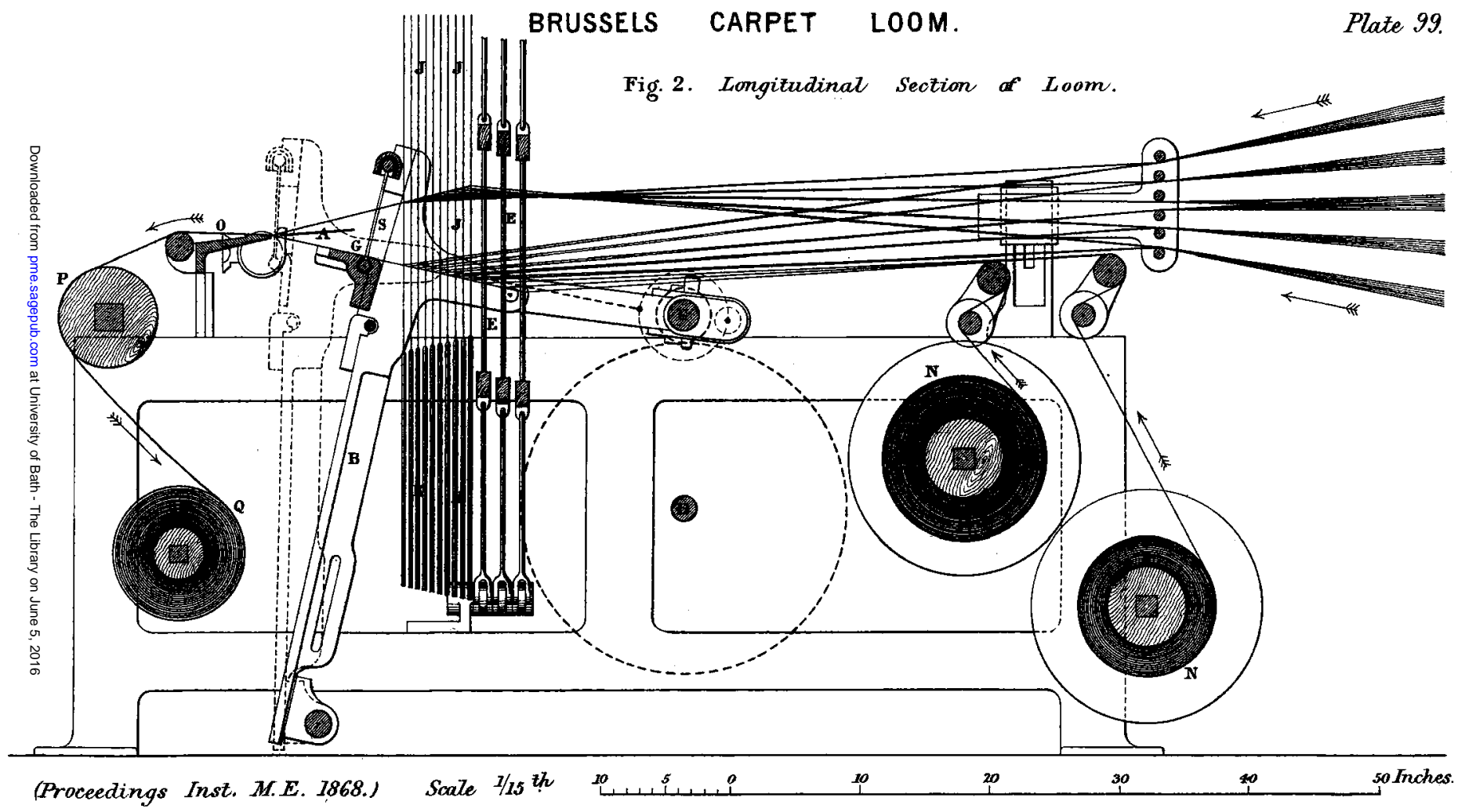


BRUSSELS CARPET LOOM.

Fig. 3. Front Elevation af Loom.

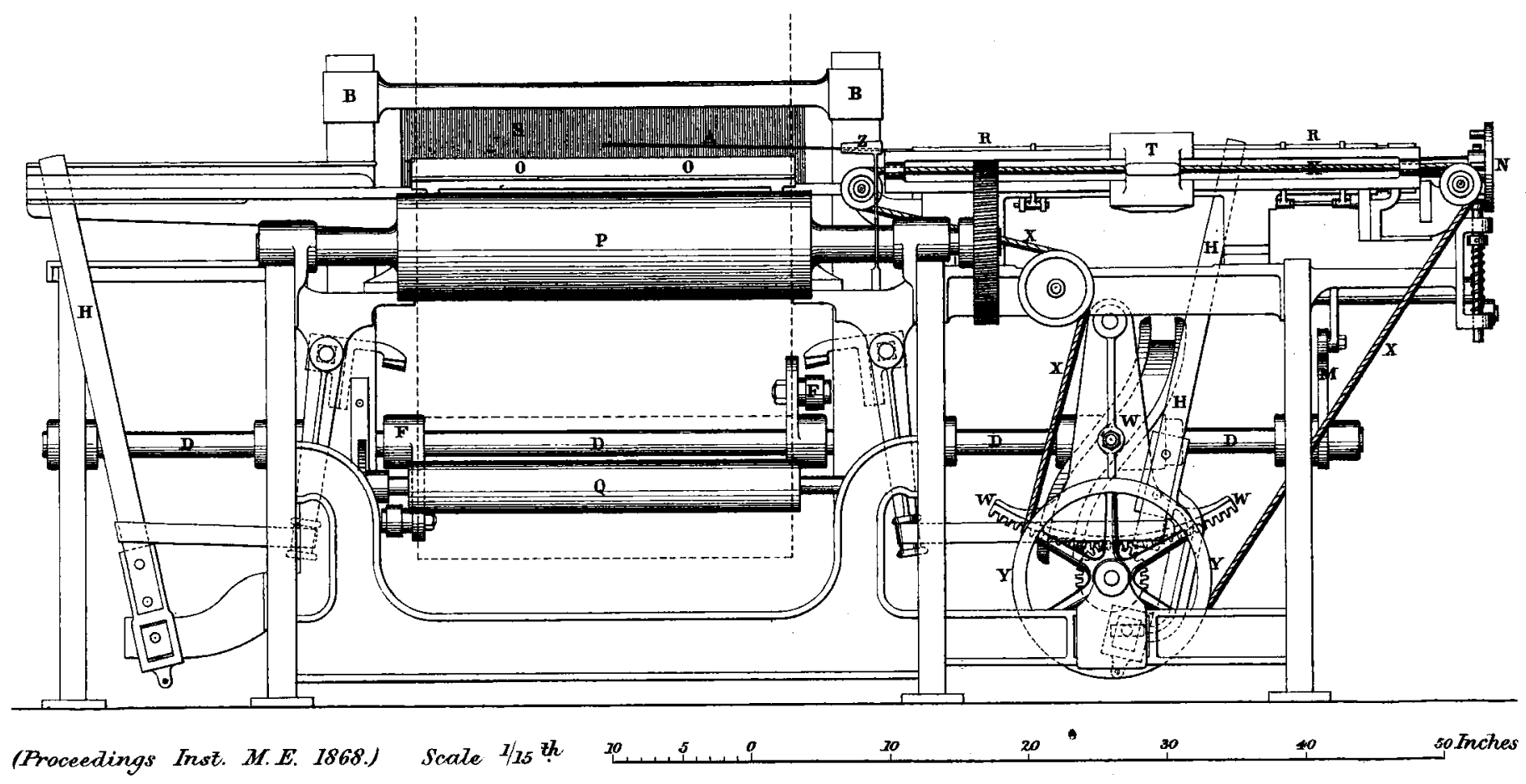


BRUSSELS CARPET LOOM. Plate 101.

Fig. 4. Plan of Creel Frame.

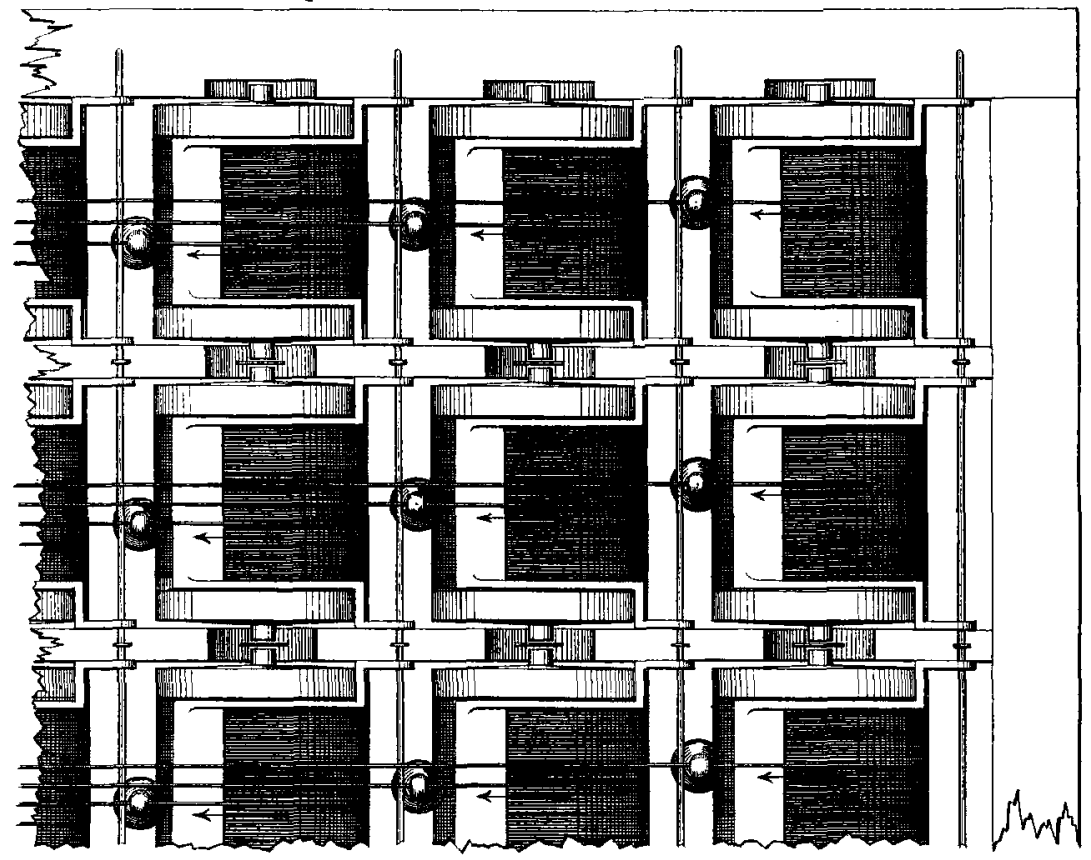

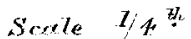

70 Fetues.

Fig. 5. Side Elevation of Creet Frame.

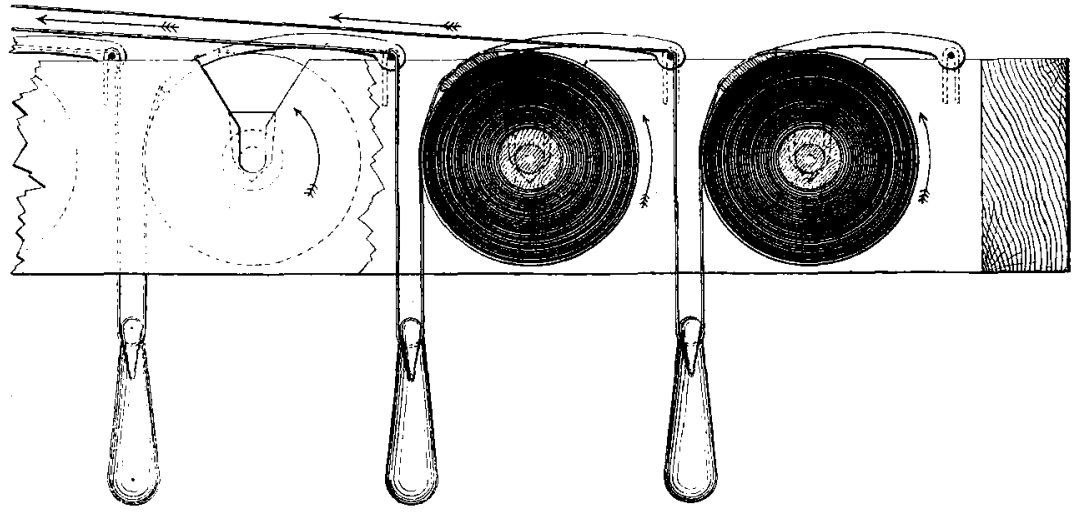

Wire for Bressets Carpet Lomn.

Fig. 6. Side Vierr.

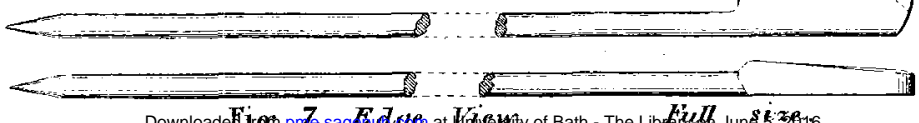

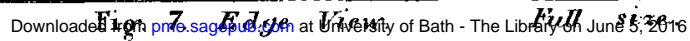

(Procededirgs: Inst. M.E. 1868.) 


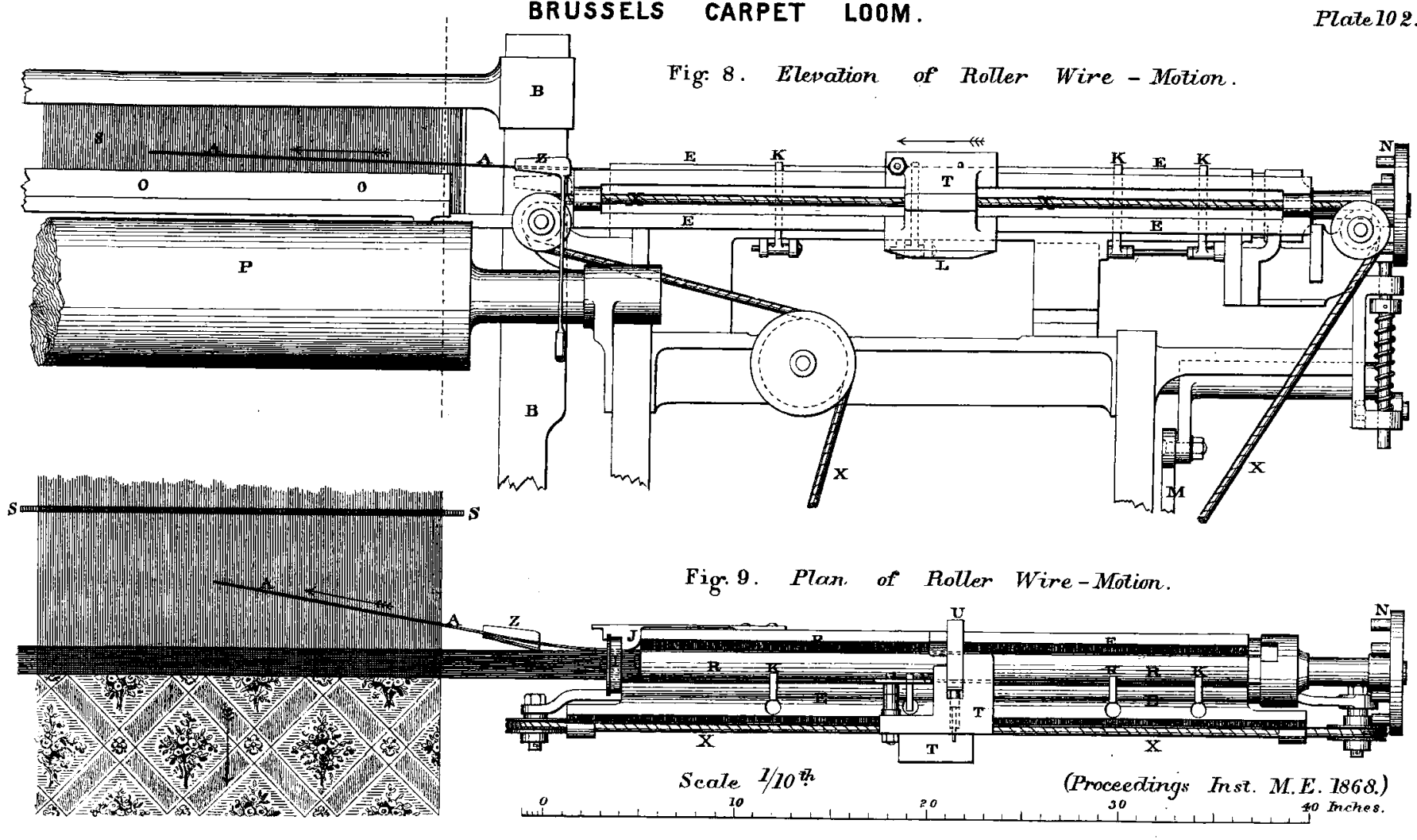


BRUSSELS CARPET LOOM. Plate 103.

Fig. 10. Transverse Section of Roller Wire-Mation. Scale $1 / 2$.
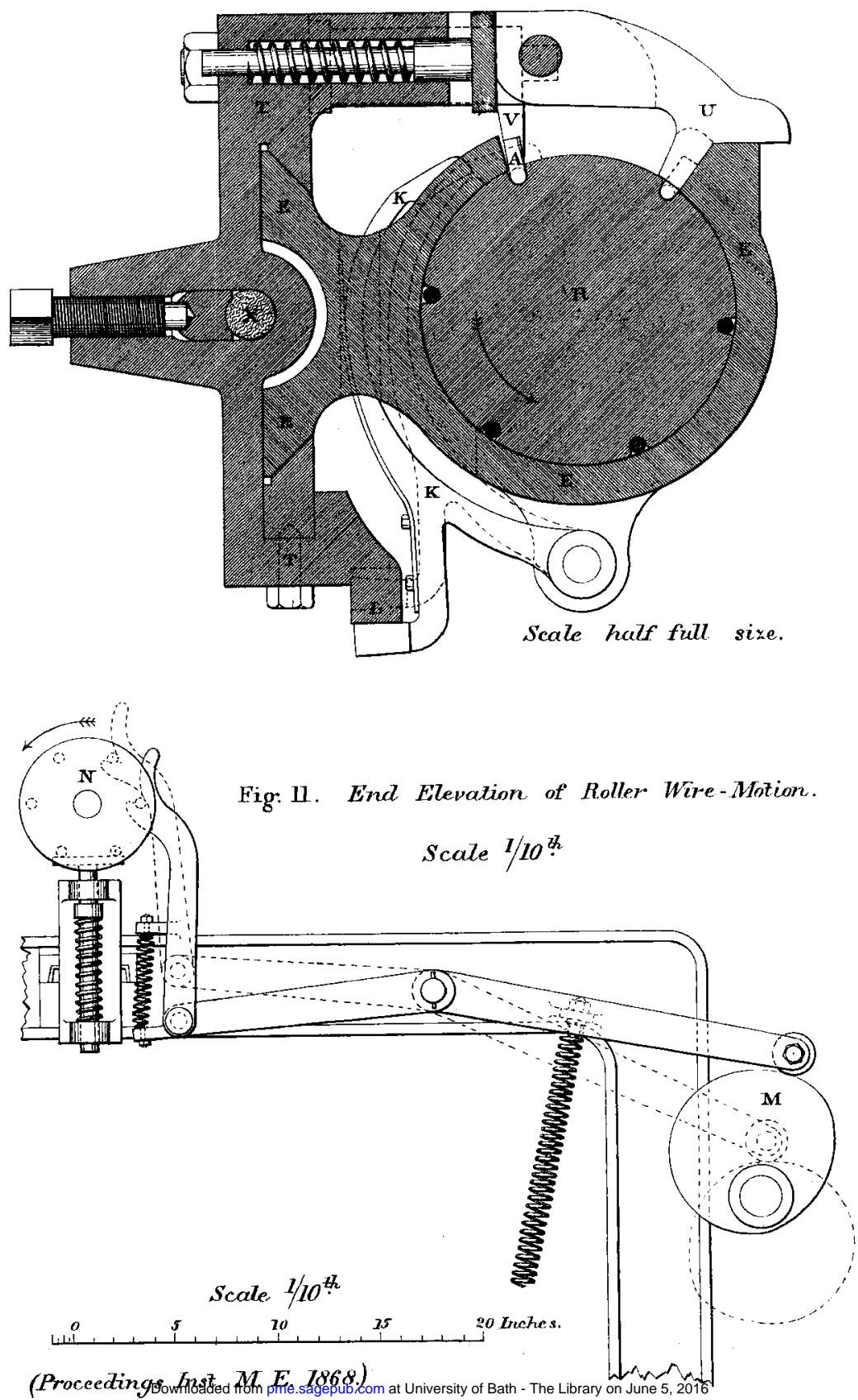
BRUSSELS CARPET LOOM. Plare 104.

Diagrams of Longitudinal Sections of Warp-pite Carpets:

Fig. 12. Tapestry Carpet.

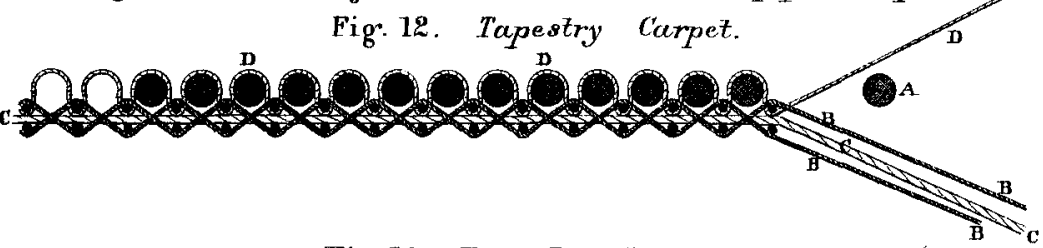

Fig. 13. Brussels Carpez.

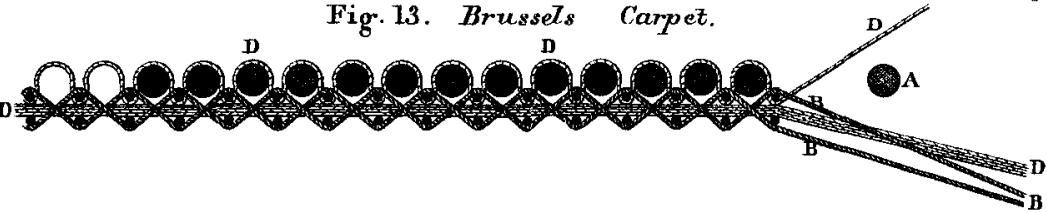

Fig. 14. Velvet or Cut-pile Corpet.

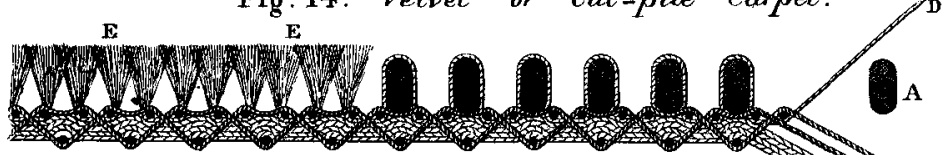

Fig: 15. Wire for weaving Velvet Carpet.
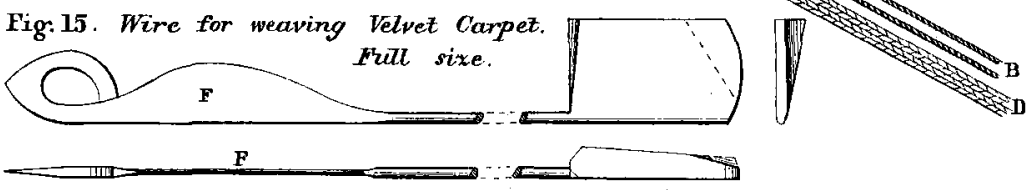

Diagrams of Sheds formed in weaving Brussels Carpet. Scale $1 / 120^{\text {th }}$ < Fig. 16. First Shed, for the shuttle.

Fig. 17. Second Shed, for the shutzle.
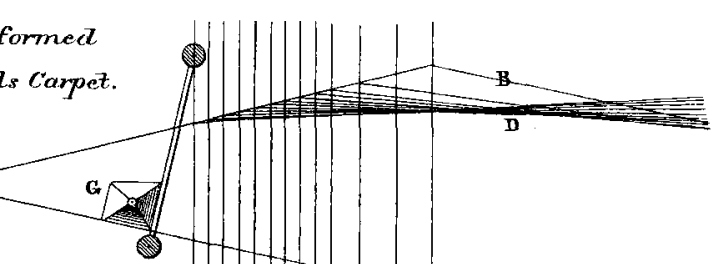

Fig. 18. Thima shed.

for the Wire. a scale $1 / 10^{\text {th }}$

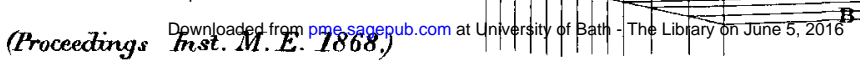

